\title{
DOSSIE
}

Sociologias, Porto Alegre, ano 15, no 34, set./dez. 2013, p. 14-25

\section{Figurações da Violência: uma apresentação enigmática}

JOSÉ VIGENTE TAUARES DOS SANTOS"

ALEK NICHE TEIKELRA"

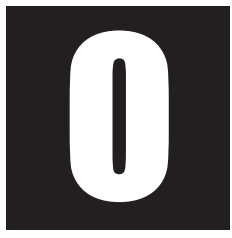

objeto deste dossiê consiste nas representações coletivas sobre a violência na modernidade, com base em uma sociologia do romance policial e do romance da violência. Propõe um conjunto de textos sociológicos sobre uma série de romances, do realismo ao romance policial e ao romance da violência na sociedade contemporânea.

A principal justificativa é a relativa ausência de estudos sobre a sociologia do romance na sociologia brasileira atual. Mais ainda, a sociologia do romance policial é praticamente inexistente na sociologia brasileira, o que se repete em relação à sociologia do cinema baseado em novelas policiais. Este dossiê se propõe a contribuir para suprir esta lacuna.

Os marcos intelectuais da sociologia do romance são Lukács, Bakhtin, Goldman, Auerbach, Antonio Candido e Roberto Schwartz. A sociologia do romance parte da questão da representação que aparece na cultura ocidental pela obra de Aristóteles, ao analisar as diferenças entre a epopeia e a tragédia, firmando os conceitos de catarse (Costa Lima, 2009, p. 720), de mimesis (Auerbach, 2007), enquanto um sentido do real ou de

\footnotetext{
*Universidade Federal do Rio Grande do Sul (UFRGS), Porto Alegre, Rio Grande do Sul, Brasil. ** Universidade Federal do Rio Grande do Sul (UFRGS), Porto Alegre, Rio Grande do Sul, Brasil.
} 
equivalente possível (Dubois, 2000, p. 28; 2006), constituindo-se a mimesis como figuração séria da realidade em Auerbach (Waizbort, 2007; Goldmann, 1990; Frederico, 2006; Schuler, 2000).

Dentre as representações coletivas que constituem a Modernidade, encontramos o crime, a polícia e a violência nos romances de aventuras e nos romances do real, sem esquecer a fotografia, desde meados do Século XIX (Dubois, 2000; Sontag, 2003; Martins, 2008). A transição da sociedade feudal para a sociedade capitalista se expressa na obra de Cervantes, pela ironia e loucura, no demonismo do real em Don Quijote (Costa Lima, 2009; Auerbach, 2007).

A emergência da forma romanesca, desde o Século XVIII, com o romance de aventura inglês (Defoe, Hilferding) consiste em uma das primeiras expressões da sociedade do Indivíduo, que viriam a assumir maior concretude por efeito da Revolução Francesa, seja pela emergência de uma socialidade "dos de baixo" (Dubois, 2000, P. 43), seja pela figura de Napoleão Bonaparte, cuja trajetória se expressaria em grandes romances do real do Século XIX (Robert, 1972). Do romance realista de Balzac, Dickens, Stendhal, Flaubert ao naturalismo de Zola, aparecia nos escritores a ambição de reconstruir social e historicamente a "comédia humana". Sabemos das dificuldades da sociologia em se constituir como saber face à literatura realista e à ciência darwiniana (Lepenies, 1996).

A empreitada novecentista possibilitou uma autonomização da literatura, a constituição do Campo Literário (Bourdieu, 1998), já com o aparecimento da dimensão moral do realismo, com larga audiência folhetinesca coincidindo com o individualismo da sociedade moderna em formação (Watt, 2007). As variadas contribuições dos novelistas à teoria da forma romanesca (Chartier, 2007) levaram a um adensamento da teoria do romance, na forma estruturada da narrativa, ou forma da linguagem - escritura, escrita, intertextualidade, metalinguagem, alegoria e metonímia. 
O conteúdo da forma romanesca compunha-se por um enigma social, com abrangência e detalhe, o que o credenciava como conhecimento e meio para transformar o mundo, eivado de historicidade e de uma duração temporal. O romance efetivava um modo de reconstrução do objeto social (Dubois, 2000, p. 46-49), marcado pelo plurilinguismo (Bakhtin, 1993), em um contorno de uma grande narrativa totalizante (Dubois, 2000, p. 76). Em termos dos personagens, o novecentismo produziu diversas personificações do herói problemático, principalmente no romance histórico (Lukacs, 1916, 2011)

As formas do romance que aparecem ainda no século XIX expressaram outras facetas da sociedade. O Romance da Desilusão, em Flaubert; o Romance da formação ou da educação, por exemplo, em Goethe e Flaubert; o Romance da "ética metafísica" ou a "metafísica da épica" marcado por Dostoievski, cujos personagens efetivavam uma ação heroica e luciferina (Lukacs, 1916; Schuler, 2000). Sem esquecer a literatura da desrazão e do mal, cara a Michel Foucault (Machado, 2005).

O romance policial aparece em Poe, nos Estados Unidos, recuperado posteriormente por Baudelaire e Borges, e em Conan Doyle, com o crime, o personagem do detetive privado, e a trama da investigação. Os temas recorrentes eram o dinheiro, o poder, o sexo, e a diferenciação e a distinção social (Mandel, 1988). Ao mesmo tempo, o romance da injustiça ou da opacidade de Kafka prefigura os totalitarismos do Século XX: desde a primeira crise da modernidade, encontramos na obra de Kafka a expressão das metamorfoses da injustiça e do poder disciplinar e burocrático na sociedade contemporânea (Deleuze \& Guattari, 1975; Lowy, 2005; Carone, 2009; Lahire, 2010).

Grande parte da literatura, desde o realismo, retoma o mesmo retrato em sépia dos de "fora da sociedade" (outsiders), com personagens os quais ora querem destruir a ordem pública, ora cometem crimes, ora 
mantém a ordem social reafirmando a racionalidade moderna (Kracauer, 2010; Ferri, 2001; Priestman, 2003). Configura uma representação que coincide com a emergência da Psiquiatria e da Sociologia: uma episteme do enigma, da investigação, da causalidade e da interpretação que visa problematizar os conflitos entre uma realidade aparente e uma realidade profunda, escondida, por vezes ameaçadora (Boltasnki, 2012). Eis o lugar do Romance Policial na Modernidade.

Podemos começar apresentando uma Tipologia do Romance Policial:

1. O Romance do Enigma - Com Edgar Allan Poe (1809-1849), surge o personagem do detetive privado, caracterizado pela habilidade, pela honra, com uma lógica dedutivo-indutiva e misógino. A figura do policial aparece como honesta, mas que trabalha sem imaginação. Dois grandes autores o sucedem: Arthur Conan Doyle (1859-1930), cujo enigma é um desemaranhar as coisas, com o desenrolar da ação, sendo o culpado o indivíduo criminoso em uma sociedade aristocrática. Agatha Christie (1890-1976) leva ao máximo esta tradição, atualmente preservada por P.D. James, em uma larga tradição britânica (James, 2009; Lehman, 2008)

2. O Romance Hard-boiled - Emerge nos Estados Unidos após a Grande Depressão de 1929, sendo Dashiell Hammett (1894-1961) seu principal Autor, cujo personagem era o detetive privado, porém um sujeito comum, seguindo a mesma lógica dedutivo-indutiva. Neste ponto, a violência aparece na cena social, e a figura do policial é de uma polícia dura, mas processual. Com Raymond Chandler (1888-1959), a ficção detetivesca indica o anti-herói, solitário. Desloca-se o fulcro do enigma: a sociedade burguesa é criminógena, tanto a grande cidade quanto a pequena cidade; no mundo urbano há uma doença generalizada do corpo social; a fachada de um ambiente de altas classes mantém alianças com o submundo, orientadas pelo dinheiro, poder e sexo. Novamente, a vio- 
lência e a arma são os meios de ação do detetive. Nessa época, aparece a virtuosa relação entre o romance e o cinema, ou seja, a emergência do "cinema noir" no qual se imortalizou la femme fatale! (Cassuto, 2008)

3. O Romance do Policial "Procedural" está presente em Georges Simenon (1903-1989), com a vida cotidiana de Maigret, o qual retoma a polícia processual e honesta, marcado por uma gastronomia sofisticada, com relações complicadas com as mulheres. Este gênero acirra o caráter de produto da indústria cultural, iniciado nos Estados Unidos e agora transladado à Europa, sendo curioso notar que na França os primeiros romances policiais de Autores franceses eram publicados sob pseudônimos ingleses (Vanoncini, 2002; Pouy, 2008; Casta, 2012; Scaggs, 2005)

4. O Romance do Justiceiro - novamente nos Estados Unidos, está presente em George Himes, em seu texto sobre a "Selva urbana", os guetos de Nova lorque, o racismo e a violência; e em Patrícia Highsmith (1921-1995), a qual escreve sobre uma sociedade urbana segmentada, com violências, em simbiose com o "submundo" e a presença da extorsão e da chantagem. Poderíamos aqui situar Jean Patrick Manchette (1942-1995), Walter Mosley (1952), Paul Auster (1947-) e James Ellroy (1948-), produção literária atualizada pelo romance policial sueco de Stieg Larsson (1954-2004). Ou seja, defende um número especial de Les Temps Modernes, fundada por Sartre, trata-se de uma escrita engajada e ofensiva porque, ao exibir os mecanismos que explicam o por quê das coisas e dos atos, denuncia os procedimentos de mentira, de alienação e de violência que preenchem nosso espaço social (Pons, 1997).

5. O Romance de Espionagem enquanto novela de suspense aparece fortemente após a II Guerra Mundial, com componentes de suspense, como em John Le Carré e lan Fleming. Com o final do Bloco Soviético, evidentemente esta temática perde vigor na literatura mundial, sendo, aos poucos, substituída pela temática do terrorismo internacional. 
6. O Romance da violência: na forma romanesca da sociedade contemporânea, a violência pode ser percebida, na literatura latino-americana, por exemplo, nas novelas do "real maravilhoso" sobre os Ditadores na América Latina, brilhantemente analisados por Octavio lanni (1993): (Miguel Angel Asturias (1899-1974); Uslar Pietri (1906-2001); Alejo Carpentier (1904- 1980); Augusto Roa Bastos (1917-2005); Gabriel Garcia Marques (1927 -); Carlos Fuentes (1928-2012); e Vargas Llosa (1936 -).

$\mathrm{Na}$ literatura brasileira, os temas da violência talvez possam ser visualizado em um percurso de Machado de Assis a Euclides da Cunha, de Érico Verissimo a Ruben Fonseca (Bosi, 1994, 1999; Candido, 2006; 2006b; Schwartz, 2000, 2000b; Fischer, 2008).

O romance policial surgiu no Brasil nos anos de 1920, com o livro Mistérios (escrito por Coelho Neto, Afrânio Peixoto, Medeiros e Albuquerque, e Viriato Correa) no qual já havia uma crítica cômica do sistema judiciário (Reimão, 2005, p. 17). Desde então, com Maria Alice Barroso, Glauco Rodrigues Correa, Carlos de Souza, Fernando Sabino, adquire densidade e expressividade cultural, atualmente pelos autores Tabajara Ruas, Tony Belloto, Patrícia Mello, Joaquim Nogueira, Reginaldo Prandi, entre outros (Albuquerque, 1979; Reimão, 2005; Figueiredo, 2003).

O eixo do enigma passa a ser a crueldade em forma romanesca, a violência nas relações sociais adquirindo centralidade. Certamente, os autores mais importantes são Ruben Fonseca e Garcia Roza, os romances de Fonseca tendo sido tematizados em vários filmes recentes.

A compreensão da representação dos meios de comunicação sobre o crime e a violência no período que recobre os últimos anos do século XX e a primeira década dos anos 2000, passa em grande medida pela análise do cinema (Menezes, 2001). Nesse cenário, convergem duas grandes tendências contemporâneas do campo da comunicação: a primeira diz respeito à mistura de informação com entretenimento, o que se eviden- 
cia na dramatização das histórias de crimes reais; e a segunda tendência consiste em propiciar à audiência uma forma ampliada de interação com a representação da narrativa romanesca (Teixeira, 2009).

A mesma representação da violência na sociedade aparece na ficção científica, expressando formas sociais contemporâneas em projeções de tecnologias do futuro.

Os textos neste dossiê realizam uma explanação sociológica internacional desta complexidade social, mediante análises de "Figurações da Violência".

No artigo "O Panorama das Drogas no México: da margem da sociedade ao centro da cultura", Diana Palaversich reconstrói o percurso das manifestações culturais ligadas ao tráfico de drogas naquele país, as quais deixaram - a partir dos narcocorridos (música) e do narcocine - sua posição marginal em relação à cultura dominante nos anos 70 e 80, para ocuparem lugar de destaque atualmente nos meios de comunicação mexicanos, bem como nas artes visuais e na literatura.

Também acerca do México, e a partir do atual contexto de guerra às drogas, Joachim Michael enfoca a constituição da narcoliteratura enquanto gênero literário no artigo "Narco-violencia y literatura en México". O autor argumenta que a narcoliteratura e a narconovela operam como designações de gênero muito pobre, mas que ao menos reúnem em nível temático os textos literários que se dedicam ao problema do narcotráfico. Estes, ao contrário dos narcocorridos, não são produções feitas ou a serviço dos narcotraficantes e, talvez por isso, discutem o narcotráfico como uma realidade inevitável, opondo-se a ele e à violência envolvida.

Em "Contar hoy la violencia de ayer: video y literatura actual sobre la transición política española", Pablo La Parra Pérez e Julio Souto Salom propõem um diálogo entre a análise sociológica e a interpretação crítica de obras literárias e de vídeo para interpretar a violência social no 
período da transição política de 1973 a 1985 na Espanha. Os autores vislumbram uma grande divergência entre os discursos construídos sobre o período, que incluem desde uma visão celebratória, instituída como discurso dominante sobre a transição e presente nos textos literários de gênero policial, até uma perspectiva crítica sobre a transição, apresentada nos vídeo-ensaios contemporâneos.

Nilia Viscardi também parte da produção literária para analisar a violência social no artigo "De muertas y policías. La duplicidad de la novela negra en la obra de Roberto Bolaño". Tendo como base a ideia de que a representação da morte subjaz a toda sociedade, a autora propõe questionamentos sobre a possibilidade de representação da morte quando esta é inesperada e quanto a possibilidade e limites de uma sociologia dessas representações. A obra "2666" de Roberto Bolaño serve como recorte empírico para uma análise orientada pela tradição Frankfurtiana de interpretação sobre arte e modernidade presente no trabalho de Krakauer, pela qual os vínculos entre a violência contemporânea, a violência institucional da polícia e a mortalidade criminal na América Latina vão sendo traçados.

Com "Chandler no Cinema Noir: algumas reflexões sobre a simples arte de matar" , Michel Misse aborda primeiramente a adaptação de novelas de Raymond Chandler para o cinema e suas incursões como roteirista de filmes. Em um segundo momento, tendo por referência o ensaio de Chandler intitulado "A simples arte de matar", o autor discute o apelo do crime e do mistério nas representações sociais presentes na estética "noir" e suas influências ainda hoje no romance policial e de mistério.

A enorme produção romanesca e sua difusão poderiam ser percebidas como um controle moderno do imaginário. Em outras palavras, estariam mimetizadas, mesmo em uma sociedade da incerteza, as relações de poder sobre o "não controle" (Costa Lima, 2009, p. 177-182). As relações entre macro e micro poderes, recentemente permeadas pela violência como re- 
lação de excesso de poder que causa um dano físico, material ou simbólico ao outro. A cidadania dilacerada, por vezes com crueldade extrema.

A relação entre romance e sociedade, romance policial e poder, romance e a violência investiga, expõe e explica várias dimensões da sociedade contemporânea. Poderíamos concluir pela formulação de uma hipótese de trabalho: em uma Era de Mundialização das Conflitualidades, na longa trajetória romanesca da modernidade configura-se um outro gênero, o romance da violência.

Talvez os textos de "Figurações da Violência" possam ajudar a verificar esta hipótese, em um trabalho coletivo e internacionalizado. Mas, certamente, o melhor juízo virá do arguto leitor ao tentar solucionar as metamorfoses do enigma.

José Vicente Tavares dos Santos. Sociólogo, graduado em Ciências Sociais pela Universidade Federal do Rio Grande do Sul (1971), Mestre em Sociologia pela Universidade de São Paulo (1977) e Doutor em Sociologia (Doctorat d'Etat) pela Université de Paris X, Nanterre (1987). Professor Titular do Departamento e do Programa de Pós-Graduação em Sociologia da Universidade Federal do Rio Grande do Sul. Membro do Conselho Universitário da UFRGS. Pesquisador do CNPq (nível I-A), Diretor do ILEA - Instituto Latino-americano de Estudos Avançados da UFRGS, Coordenador do Grupo de Pesquisa Violência e Cidadania, desde 1995. Membro do: RC-29 Social Control and Deviance ( Vice-Presidente 20102014) da ISA - Associação Internacional de Sociologia); Conselho Diretivo do CLACSO - Conselho Latino-americano de Sociologia $(2007-2009$; 2009=2011) e do Fórum Brasileiro de Segurança Pública (2009-2011).

$\gg$ jvtavares@gmail.com

Alex Niche Teixeira. Professor Adjunto do Departamento de Sociologia e Programa de Pós-Graduação em Sociologia da Universidade Federal do Rio Grande do Sul (UFRGS). Pesquisador associado ao Instituto Nacional de Ciência e Tecnologia em Violência, Democracia e Segurança Cidadã - CNPq e do Grupo de Pesquisa Violência e Cidadania - UFRGS/CNPq. Possui graduação em Ciências Sociais (1998), Mestrado (2003) e Doutorado (2009) em Sociologia pela UFRGS. Na mesma instituição é Professor e Vice-Coordenador do Curso de Especialização em Segurança Cidadã (RENAESP/Ministério da Justiça) e gestor do Laboratório de 
Cartografias Sociais e Simbólicas (LACSS). Membro da Sociedade Brasileira de Sociologia (SBS) e da Associação Internacional de Sociologia (ISA) vinculado ao RC29 (Deviance and Social Control). Desde 1997 atua nas áreas de Metodologias Informacionais e Informática aplicada às Ciências Sociais tendo sido certificado pela QSR International como consultor independente do software NVIVO no Brasil.

$\gg$ alexnt.ufrgs@gmail.com

\section{Referências}

ALBUQUERQUE, P. M. O Mundo Fascinante do Romance Policial. Rio de Janeiro: Francisco Alves, 1979.

AUERBACH, E. Mimesis. São Paulo: Perspectiva, 2007.

BAKHTIN, M. Questões de literatura e de estética. São Paulo: Hucitec, 1993.

BOLTANSKI, L. Énigmes et Complots: une enquete à propos d'enquêtes. Paris: Gallimard, 2012.

BOSI, A. Dialética da Colonização. São Paulo: Companhia das Letras, 1994.

BOSI, A. História concisa da Literatura Brasileira. São Paulo: Cultrix, 32aㅡ Ed. 1999.

BOURDIEU, P. Les regles de I'art. Paris: Seuil, 1998.

CANDIDO, A. Tese e antítese. Rio de Janeiro: Ouro sobre Azul, 2006.

CANDIDO, A. Literatura e sociedade. Rio de Janeiro: Ouro sobre Azul, 2006.

CARONE, M. Lições de Kafka. São Paulo: Companhia das Letras, 2009.

CASTA, I-R. Pleins feux sur le polar. Paris, Klincksieck, 2012.

CASSUTO, L. Hard-boiled Sentimentality (The Secret History of American Crime Stories). New York: Columbia University Press, 2008.

DELEUZE, GILLES \& GUATTARI, F. Kafka : pour une literature mineure. Paris: Minuit, 1975.

CHARTIER, P. Introduction aux grandes théories du roman. Paris: Armand Colin, 2007.

CHAVES, F. L. Érico Veríssimo: o escritor e seu tempo. Porto Alegre: Editora da UFRGS, 2001.

DUBOIS, J. Les romaciers du réel : de Balzac à Simenon. Paris: Seuil, 2000. 
DUBOIS, J. Le roman policier ou la modernité. Paris: Armand Colin, 2006. FERRI, E. Os criminosos na arte e na literatura. Porto Alegre: Ricardo Lenz, 2001 (ed. italiana de 1902).

FIGUEIREDO, V. L. F. Os crimes do texto: Rubem Fonseca e a ficção contemporânea. Belo Horizonte: Editora da UFMG, 2003.

FISCHER, L. A. Literatura Brasileira - Modos de usar. 2. ed. Porto Alegre: L \& PM Editores, 2007.

FISCHER, L. A. Machado e Borges - e outros ensaios sobre Machado de Assis. Porto Alegre: Arquipélago Editorial, 2008.

FREDERICO, C. Sociologia da cultura: Lucien Goldmann e os debates do Século XX. São Paulo: Cortez, 2006.

GOLDMANN, L. A Sociologia do Romance. Rio de Janeiro: Paz e Terra, 3aㅡ ed. 1990.

IANNI, O. O labirinto latino-americano. Petrópolis: Vozes, 1993.

JAMES, P.D. Talking about Detective Fiction. New York: Alfred A. Knopf, 2009 (1920) (Ed. Bras. Segredos do Romance Policial, São Paulo: Ed. Três Estrelas, 2012).

HORSLEY, L. Twentieth-Century Crime Fiction. New York: Oxford, 2005.

KRACAUER, S. La Novela Policial: un tratado filosófico. Buenos Aires: Paidós, 2010 (escrito em 1925, primeira edição alemã em 1971).

LEHMAN, D. The Perfect Murder: a study in detection. Ann Arbor: The University of Michigan Press, 2008.

LEPENIES, W. As três culturas. São Paulo: UNESP, 1996.

LOWY, M. \& RAGO FILHO, A. Lucien Goldmann ou a Dialética da Totalidade. Rio de Janeiro: Boitempo, 2009.

LOWY, M. Franz Kafka, sonhador insubmisso. Rio de Janeiro, Azougue, 2005.

LUKÁCS, G. A teoria do romance. São Paulo: Duas Cidades, 2000.

LUKÁCS, G. O Romance Histórico. São Paulo: Boitempo, 2011.

$M A C H A D O$, R. Foucault, a filosofia e a literatura. Rio de Janeiro: Jorge Zahar, 3를. 2005.

MANDEL, E. Delícias do Crime (história social do romance policial). São Paulo: Busca Vida, 1988.

MARTINS, J. S. Sociologia da fotografia e da imagem. São Paulo: Contexto, 2008. 
MENEZES, P. À Meia-luz: cinema e sexualidade nos anos 70. São Paulo: Editora 34, 2001.

PONS, J. Le roman noir, littérature réelle. In : Les Temps Modernes. Paris: aoûtseptembre - octobre 1997, p. 1-14.

POUY, J-B. Une brève Histoire du Roman Noir. Paris: L'Oeil Neuf, 2008.

PRIESTMAN, M. (ed.). The Cambridge Companion to Crime Fiction. Cambridge: Cambridge University Press, 2003.

REIMÃO, S. Literatura Policial Brasileira. Rio de Janeiro: Jorge Zahar, 2005.

ROBERT, M. Roman des origines et origines du Roman. Paris: Gallimard, 1972.

SCAGGS, J. Crime Fiction. London: Rouledge, 2005.

SCHULER, D. Teoria do Romance. São Paulo: ATICA, 2000.

SCHWARTZ, R. Ao vencedor as batatas. São Paulo: Editora 34, 2000.

SCHWARTZ, R. Um mestre na periferia do capitalismo. São Paulo: Editora 34, 2000.

SONTAG, S. Regarding the pain of others. New York: Picador, 2003.

TEIXEIRA, A. N. A abordagem televisiva do crime violento na modernidade tardia. 2009. Tese (Doutorado em Sociologia) - Instituto de Filosofia e Ciências Humanas, Universidade Federal do Rio Grande do Sul, Porto Alegre, 2009.

VANONCINI, A. Le Roman Policier. Paris: PUF, 2002.

WAIZBORT, L. A Passagem do três ao um. São Paulo: Cosac Naify, 2007.

WAIZBORT, L. As Aventuras de Georg Simmel. São Paulo: Editora 34, 2000.

WATT, I. A ascensão do romance. São Paulo: Companhia das Letras, 2007. 